\title{
Surgical approach for totally implantable venous access port: a full strategy to avoid the percutaneous approach complications
}

\author{
Adriana Toro $^{1}$ • Emanule Gaspare Fontana ${ }^{2}$ - Isidoro Di Carlo ${ }^{2}$ \\ Received: 15 January 2021 / Accepted: 20 January 2021 / Published online: 8 February 2021 \\ (C) The Author(s), under exclusive licence to Springer-Verlag GmbH, DE part of Springer Nature 2021
}

Dear Editor,

We read with interest the article by Klaiber et al. published online in January 2021 in the Langenbeck's Archives of Surgery [1]. The authors concluded their meta-analysis stating that the cutdown technique for totally implantable venous access port in the cephalic vein reduced the risk of pneumothorax and hemothorax when compared with closed cannulation of the subclavian vein.

We appreciate the results of the study. The cutdown technique is historically and scientifically the most intuitively safe method to prevent hemothorax and pneumothorax [2]. In unsuccessful cases, the authors suggest the closed cannulation with ultrasound technique.

However, in our opinion, the rescue technique, in case of failure to use the cephalic vein, can continue to be surgical. We have described, by the same incision, the use of either the coracobrachialis [2] or the external jugular vein [3]. These two techniques add a small amount of time during the procedure; however, in our personal experience, neither pneumothorax nor hemothorax has been experienced [4]. Furthermore, the pieces of evidence of closed cannulation with ultrasound are not still solid [1].

\section{References}

1. Klaiber U, Probst P, Hackbusch M, Jensen K, Dörr-Harim C, Hüttner FJ, Hackert T, Diener MK, Büchler MW, Knebel P (2021) Metaanalysis of primary open versus closed cannulation strategy for totally implantable venous access port implantation. Langenbeck's Arch Surg. https://doi.org/10.1007/s00423-020-02057-w

2. Di Carlo I, Puleo S (2001) A new technique for insertion of totally implantable venous access devices (TIVAD). Surgery 129:768-769. https://doi.org/10.1067/msy.2001.115351

3. Di Carlo I, Barbagallo F, Toro A, Sofia M, Lombardo R, Cordio S (2005) External jugular vein cutdown approach, as a useful alternative, supports the choice of the cephalic vein for totally implantable access device placement. Ann Surg Oncol 12:570-573. https://doi. org/10.1245/ASO.2005.04.028

4. Di Carlo I, Pulvirenti E, Mannino M, Toro A (2010) Increased use of percutaneous technique for totally implantable venous access devices. Is it real progress? A 27-year comprehensive review on early complications. Ann Surg Oncol 17:1649-1656. https://doi.org/10. 1245/s10434-010-1005-4

Publisher's note Springer Nature remains neutral with regard to jurisdictional claims in published maps and institutional affiliations.

Isidoro Di Carlo

idicarlo@unict.it

General Surgery, Augusta Hospital, Augusta, SR, Italy

2 Department of Surgical Sciences, and Advanced Technologies "GF Ingrassia”, University of Catania, Cannizzaro Hospital, Via Messina 829,95126 Catania, Italy 